\title{
ANALISIS KINESIOLOGI TEKNIK KETERAMPILAN TUBUH PADA OLAHRAGA TOLAK PELURU GAYA ORTODOCK MAHASISWA PJKR UPGRIS
}

\author{
Pandu Kresnapati \\ Jurusan Pendidikan Jasmani Kesehatan dan Rekreasi, Universitas PGRI Semarang, Semarang, Indonesia \\ *pandukresnapati@upgris.ac.id
}

(Received: July 2018 / Revised: September 2018 / Accepted: September 2018)

\begin{abstract}
ABSTRAK : Pada pembahasan penelitian ini bertujuan untuk mengetahui analisis teknik gerakan keterampilan tubuh gaya ortodock terhadap hasil tolakan pada olahraga tolak peluru yang dilihat dari segi kinesiologi (anatomi, fisiologi, dan biomekanika). Metode yang digunakan dalam penelitian adalah metode survey dengan jenis penelitian korelasioner dan menggunakan metode pendekatan kuantitatif. Populasi pada penelitian ini adalah mahasiswa PJKR semester 2 Universitas PGRI Semarang dengan jumlah populasi 213 mahasiswa, sampel pada penelitian ini adalah 40 mahasiswa putra semester 2. Teknik dalam pengambilan sampel menggunakan random sampling dengan sistem undian. Variabel penelitian ini adalah mengkorelasikan dan menganalisis teknik keterampilan tubuh gaya ortodock terhadap hasil tolakan pada olahraga tolak peluru yang dilihat dari segi kinesiologi (anatomi, fisiologi dan biomekanika) tubuh. Data yang terkumpul dianalisis menggunakan analisis deskriptif. Hasil penelitian menunjukan pengamatan keterampilan gerak tubuh dengan gaya ortodock terhadap hasil tolakan pada olahraga tolak peluru dilihat dari segi anatomi dengan jumlah $76,61 \%$ dengan kategori baik. Hasil dari keterampilan gerak tubuh pada gaya ortodock terhadap hasil tolakan pada olahraga tolak peluru dilihat dari segi biomekanika jumlah $62,81 \%$ dengan kategori baik. Teknik keterampilan tubuh gaya ortodock terhadap hasil tolakan pada olahraga tolak peluru mahasiswa semester 2 PJKR Universitas PGRI Semarang pada tahun 2018 yang dilihat dari segi kinesiologi (anatomi, fisiologi, dan biomekanika) dalam kategori baik dengan jumlah kriteria penilaian $72,63 \%$ kategori baik.
\end{abstract}

KATA KUNCI : $\quad$ Kinesiologi, Tolak Peluru, Mahasiswa PJKR UPGRIS.

ABSTRACTS : In the discussion of this study aims to determine the analysis of orthodock style body skills movement techniques against repulsion results in the sport of bulletproof which is seen in terms of kinesiology (anatomy, physiology, and biomechanics). The method used in the study is a survey method with the type of correlational research and uses a quantitative approach method. The population in this study were the 2nd semester students of Semarang PGRI University with a population of 213 students, the sample in this study were 40 male students of semester 2 . The technique in sampling used random sampling with a lottery system. The variables of this study were to correlate and analyze orthodock-style body skills techniques against repulsion results in the exercise of bullets which were seen in terms of kinesiology (anatomy, physiology and biomechanics) of the body. The collected data were analyzed using descriptive analysis. The results showed observations of orthodock-style body movement skills on repulsion results in bulletproof sports seen in terms of anatomy with a number of $76.61 \%$ with good categories. The results of body movement skills on orthodock force on repulsion results in bullet repellent sports are seen in terms of biomechanics, with 62.81\% in the good category. Orthodock style body skill techniques on repulsion results on the bulletproof sport of PJKR semester 2 students Semarang PGRI University in 2018 which was seen in terms of kinesiology (anatomy, physiology, and biomechanics) in good category with $72.63 \%$ assessment criteria in good category.

KEYWORD (10 Bold): $\quad$ Kinesiologi, Reject Bullet, UPGRIS PJKR Student. 


\section{PENDAHULUAN}

Atletik adalah sekumpulan olahraga yang meliputi lari, jalan, lempar dan lompat yang telah menjadi olahraga tertua dalam peradaban manusia (Achmad Fauzi 2015:3) Atletik merupakan salah satu cabang olahraga yang tertua di dunia. Prestasi olahraga yang ada di dunia dan terutama di indonesia saat ini sudah jauh dari kata "Kurang memuaskan" terlihat pada saat kejuaraan olympiade rio kemarin untuk Indonesia tidak dapat mengirimkan perwakilan atlet dari cabang atletik karena dari berbagai macam event atan kejuaraan kejuaran atletik di Indonesia baik tingkat daerah, nasional maupun dalam tingkat internasional, indonesia belum dapat dikatakan memiliki prestasi yang maksimal, padahal jika dilihat dari letak wilayah Indonesia dan banyaknya rakyat Indonesia tidaklah sulit jika mencari bakat-bakat dari masing-masing individu dalam lingkup olahraga dalam hal ini adalah atlet atletik.

Menurut Iman Imanudin (2011:1) Atlet tolak peluru yang memiliki struktur anatomi yang tinggi badan dan berat badan yang lebih besar akan menghasilkan prestasi yang lebih baik selain itu juga sudut saat lepas. Tolak peluru memiliki beberapa gaya pada saat melakukannya, seperti halnya gaya ortodock dan bahkan ada beberapa yang hanya menggunakan gaya standing pada saat melakukannya. Diantara beberapa gaya dalam tolak peluru gaya ortodock atau gaya menyamping ini yang sering dilakukan olah para atlet tolak peluru dan seperti halnya pemula disini adalah mahasiswa PJKR UPGRIS.

Dwi Rizki Ambarwati (2017:3) Koordinasi merupakan kemampuan yang dapat mempengaruhi akurasi dalam keterampilan tolak peluru. Unsur-unsur biomekanika yang terpenting pada posisi tolak pada posisi menolak. Gerakan harus fokus yang dititik beratkan pada bagian kaki yang terkuat pada saat melakukan gerakan dengan posisi tangan yang satu aktif sebagai penyeimbang gerakan. Posisi badan dicondongkan pada bagian kanan dengan posisi kaki ditekuk dan peluru diletakkan pada bagian leher sebelum melakukan tolakan. Setelah dirasa siap maka gerakan eksplosif disini diperlukan agar menghasilkan power yang cepat sehingga daya dorong badan terhadap tekanan peluru menjadi lebih ringan dan hasil dari tolakan bisa maksimal lebih jauh dengan memperhatikan sudut lemparan. Serta diakhiri dengan kaki memutar maupun kesamping agar pelempar tidak keluar dari posisi dari lapangan tolak.

Tolak peluru di regional Indonesia dan yang di ajarkan di sekolah-sekolah maupun perguruan tinggi pada jurusan pjkr sering menggunakan gaya ortodock atau menyamping dibandingkan dengan menggunakan gaya o-brian yang dianggap sulit karena memerlukan kekuatan otot paha dan keseimbangan dalam melakukannya. Khomsin (2008:58) mengatakan dalam pelaksanaan awalan dengan gaya ortodock menjadikan patokan tubuh dibagian kanan menjadi tumpuan terberat pada saat akan melakukan tolakan. Karena semua titik berat akan berpusat pada kaki kanan yang memiliki gerakan lanjutan untuk dicondongkan dan diayun keatas untuk mendapatkan gerakan kecepatan pada saat melakukan tolakan.

Ngadenan (2010:41) Analisis Kinisiologi adalah untuk mengenali sendi-sendi, otot-otot, dan tuas-tuas tulang yang digunakan dalam ketangkasan. Informasi ini dapat diperoleh dari studi electromygraphic yang dilakukan dalam ketangkasan dari pelatih yang berpengalaman dan mengenal baik anatomi (ilmu urai) yang berhubungan dengan olahra. Menurut Ade Satria Bagus S (2014:4) Analisis gerakan dalam olahraga sangat perlu dilakukan baik oleh pelatih maupun ahli biomekanik untuk memperbaiki gerakan yang salah. Pada proses pembentukan tolak peluru gaya ortodock yang baik dan benar tidak hanya mengandalkan pengamatan secara sepintas yang tidak dapat ditangkap oleh mata kita, sehingga 
diperlukan dukungan ilmu pengetahuan dan teknologi.

Perguruan tinggi selain sebagai lembaga Pendidikan formal dijenjang lanjutan setelah menengah atas juga dapat berfungsi sebagai tempat untuk mengembangan dan pembinan cabang olahraga disini dimaksudkan adalah olahraga tolak peluru dengan gaya ortodock. Menurut Nurhayati (2017: 3) teknik yang harus dikuasai dalam melakukan tolak peluru adalah cara memegang peluru, teknik menempatkan peluru, persiapan awal, awalan sikap badan akan menolak dan cara menolakkan peluru. Dengan didukungnya sarana dan prasarana yang memadai diharapkan para mahasiswa ketika mengikuti pembelajaran maupun pembinaan olahraga atletik dapat dilakukan secara maksimal dan kontinyu. Karena disalah satu mata kuliah yang harus didapat oleh mahasiswa salah satunya adalah mata kuliah atletik yang tergolong banyak nomor yang harus dipelajari didalamnya meliputi nomor lari, lompat, lempar maupun tolak.

Berdasarkan permasalahan diatas peneliti tertarik untuk melakukan penelitian untuk meneliti maupun menganalisa tehnik keterampilan gerak tubuh mahasiswa pada materi pembelajaran tolak peluru menggunakan gaya ortodock terhadap hasil tolakan pada olahraga tolak peluru yang dtinjau dari segi Kinesiologinya. Disini masalah yang timbul adalah bagaimana cara menganalisa teknik keterampilan gerak tubuh gaya ortodock terhadap hasil tolakan pada olahraga tolak peluru yang dilihat dari segi kinesiologinya. Dari masalah tersebut memiliki tujuan yaitu untuk mengetahui analisis tehnik gerak tubuh gaya ortodock dengan hasil tolakan pada olahraga tolak peluru mahasiswa PJKR UPGRIS.

\section{METODE PENELITIAN}

Metode yang digunakan dalam penelitian ini adalah metode survey dengan cara mendokumentasikan dan melakukan observasi. Populasi dalam penelitian ini adalah mahasiswa semester 2 PJKR UPGRIS, sedangkan sampel pada penelitian ini berjumlah 40 mahasiswa dengan teknik pengambilan sampelnya menggunakan random sampling dengan cara undian. Variabel bebas pada penelitian ini adalah analisis kinesiologi. Untuk variabel terikatnya adalah hasil tolakan (teknik keterampilan gerak tubuh). Instrumen yang diterapkan dalam penelitian ini meliputi 1. Pengukuran berat dan tinggi badan badan. 2. Observasi gerakan untuk mengetahui korelasi atau analisis teknik tolak peluru dengan gaya ortodock yang dilihat dari gerakan kinesiologi tubuh (anatomi, fisiologi dan biomekanika). Analisis yang digunakan dalam penelitian ini menggunakan tehnik deskripsi presentase (Suharsimi Arikunto, 2006:38)

\section{HASIL}

Deskriptif data dari tiap-tiap komponen keterampilan gerak tubuh tolak peluru gaya ortodock terhadap hasil tolakan pada olahraga tolak peluru mahasiswa semester 2 PJKR UPGRIS 2018 diperoleh hasil data sebagai berikut :

Tabel 1. Dari Segi Anatomi dan gerak tubuh

\begin{tabular}{ccc}
\hline $\begin{array}{c}\text { Segi Anatomi dan } \\
\text { Fisiologi }\end{array}$ & Sesuai & Tidak Sesuai \\
\hline Jumlah & 613 & 187 \\
\hline Presentase & $74,61 \%$ & $25,29 \%$ \\
\hline Kategori & & Baik \\
\hline
\end{tabular}

Tabel 2. Ringkasan Data Dari Segi Biomekanika Tubuh

\begin{tabular}{ccc}
\hline Segi Biomekanika & Sesuai & Tidak Sesuai \\
\hline Jumlah & 524 & 276 \\
\hline Presentase & $62,81 \%$ & $37,19 \%$ \\
\hline Kategori & & Baik \\
\hline
\end{tabular}

Tabel 3. Ringkasan Data Segi Kinesiologi

\begin{tabular}{ccc}
\hline Variabel & Sesuai & Tidak Sesuai \\
\hline $\begin{array}{c}\text { Anatomi dan } \\
\text { Fisiologi }\end{array}$ & 613 & 187 \\
\hline Biomekanika & 524 & 276 \\
\hline Jumlah & 1137 & 463 \\
\hline Presentase & $72,63 \%$ & $27,27 \%$ \\
\hline Kategori & & Baik \\
\hline
\end{tabular}




\section{PEMBAHASAN}

Hasil penelitian yang ada, maka dipaparkan suatu pembahasan tentang hasil penelitian. Pembahasan ini berupa penguraian hasil penelitian analisis kinesiologi teknik keterampilan tubuhpada olahraga tolak peluru gaya ortodock mahasiswa PJKR UPGRIS.

Dilihat dari tabel 1 hasil pengamatan keterampilan gerak tubuh dengan gaya ortodock terhadap hasil tolakan pada olahraga tolak peluru dilihat dari segi kinesiologi terhadap mahasiswa semester 2 PJKR UPGRIS berjumlah 40 mahasiswa atau sampel penelitian menggunakan 35 indikator pengamatan pilihan dan yang tidak sesuai, menunjukan indikator kriteria dengan jumlah $76,61 \%$ dengan kategori baik.

Dilihat dari tabel 2 hasil keterampilan gerak tubuh pada gaya ortodock terhadap hasil tolakan pada olahraga tolak peluru mahasiswa semester 2 PJKR UPGRIS dilihat dari segi biomekanika terhadap 40 mahasiswa dengan menggunakan 35 butir indikator pengamatan pilihan sesuatu dan yang tidak sesuai, menunjukan indikator kriteria dengan jumlah $62,81 \%$ dengan kategori baik.

Dilihat dari tabel 3 hasil teknik gerak dengan menggunakan gaya ortodock terhadap hasil tolakan pada olahraga tolak peluru mahasiswa semester 2 pjkr upgris dilihat dari segi kinesiologinya (anatoimi, fisiologi, dan biomekanika) terhadap 40 sampel mahasiswa yang menggunakan 70 butir indikator pengamatan pilihan sesui dan yang tidak sesuai menujukan nilai indikator kriteria dengan jumlah $72,63 \%$ dengan kategori baik.

\section{SIMPULAN DAN REKOMENDASI}

Berdasarkan dari hasil penelitian dan pembahasan diatas, maka dapat diambil sebuah kesimpulan bahwa keterampilan gerak tubuh gaya ortodock terhadap hasil tolakan pada olahraga tolak peluru yang dilakukan oleh mahasiswa semester 2 PJKR UPGRIS pada tahun 2018 dalam kategori "baik" dengan rincian sebagai berikut Teknik keterampilan gerak tubuh dengan gaya ortodock terhadap hasil tolakan pada olahraga tolak peluru mahasiswa semester 2 PJKR UPGRIS pada tahun 2018 dilihat dari segi kinesiologi dalam kategori baik. Teknik keterampilan gerak tubuh dengan gaya ortodock terhadap hasil tolak pada olahraga tolak peluru dilihat dari segi biomekanika dalam kategori baik. Teknik keterampilan gerak tubuh dengan gaya ortodock terhadap hasil tolak pada olahraga tolak peluru mahasiswa semester 2 pjkr upgris pada tahun 2018 dilihat dari segi kinesiologi (anatomi, fisiologi dan biomekanika) dalam kategori baik.

\section{UCAPAN TERIMAKASIH}

Terimakasih kami ucapkan kepada berbagai pihak yang telah membantu dan mensukseskan penelitian yang saya lakukan terutama bagi para mahasiswa-mahasiswa saya yang sudah berkenan menyempatkan waktunya dan tenaganya guna untuk pengambilan data penelitian untuk saya.

\section{REFERENSI}

Ambarwati, Dwi Rizki, Widiastuti Widiastuti, and Karisdha Pradityana. "Pengaruh daya ledak otot lengan, kelentukan panggul, dan koordinasi terhadap keterampilan tolak peluru gaya O'Brien." Jurnal Keolahragaan 5.2 (2017): 207-215.

Fauzi, Achmad. "Perbandingan Gaya O'brien Dan Gaya Ortodok Terhadap Hasil Belajar Tolak Peluru (Siswa Kelas VIII MTs Salafiyah Syafi'iyah Bandung Diwek Jombang Tahun Pelajaran 2014/2015)."

Imanudin, Imam. (2011). Analisa Prestasi Hasil Tolakan Pada Cabang Olahraga Atletik Nomor Tolak Peluru. Bandung : Abstrak Jurnal Kepelatihan Olahraga Universitas Pendidikan Indonesia.

Jonath, U. (1992). Atletik 2-Lempar dan Lomba Ganda.Jakarta : PT. Rosda Jaya Putra, ISBN : 979-426-037-1. 
Khomsin. (2008). Atletik 2 (Dasar-dasar

Pembelajaran Atletik, Lompat Jangkit, Lari Gawang, Lempar Lembing, Lompat Tinggi, Lempar Cakram, Lari Estafet, Jalan Cepat, dan Peraturan Perlombaan.Semarang : Universitas Negeri Semarang Press, ISBN : 979-1006-63-6.

Malang, Dosen UT UPBJJ. "Pembinaan Olahraga Prestasi Bola Voli Ditinjau Dari Aspek Kinesiologi Dan Biomekanika."

Nuryati, Nuryati, Arwin Arwin, and Bogy Restu Ilahi. "Upaya Peningkatan Proses Belajar Atletik Tolak Peluru Melalui Penerapan Media Poa Pada Siswa Kelas V Sd Negeri 05 KOta Bengkulu." KINESTETIK 1.2 (2017).

Purnomo, Eddy. (2011). Dasar-dasar Gerak Atletik. Yogyakarta : Alfamedia, ISBN : 978-97912974-1-7.

Satria Bagus S, a. D. E. "Analisis Gerak Lempar Lembing (Studi Pada Atlet Atletik Cabor Lempar Lembing PASI Sidoarjo, Ditinjau dari Aspek Biomekanika dan Kinesiologi)." Jurnal Kesehatan Olahraga 2.1 (2014).

Suharsimi Arikunto. (2006). Prosedur Penelitian

Dan Pendekatan Praktis. Jakarta : Rineka

Cipta CV. Alfabeta 